\title{
Perception of Peduli Sihat Scheme among Peduli Sihat Users
}

\author{
Ahmed $\mathrm{J}^{1 *}$, Selvaganapathi $\mathbf{G}^{2}$, Dinesh $\mathbf{M}^{3}$, Azra $\mathbf{N}^{1}$, Harikrishnan $\mathrm{T}^{4}$, Kohila JR ${ }^{1}$, Fathy $\mathbf{~}^{5}$, Ramalinggam $\mathbf{R}^{1}$, Mathialagan AG ${ }^{1}$, Tee $\mathrm{HY}^{6}$ and \\ Vanita $\mathbf{S}^{7}$ \\ ${ }^{1}$ School of Post-Graduate Studies, Perdana University, Malaysia \\ ${ }^{2}$ Seremban Prison, Malaysian Prison Department, Home Ministry, Malaysia \\ ${ }^{3} \mathrm{SP}$ Care Group, Health Care, Malaysia \\ ${ }^{4}$ Department of Rehabilitation Medicine, Hospital Tunku Ampuan Rahimah, Ministry of Health, Malaysia \\ ${ }^{5}$ Child Health Department, Sabak Bernam District Health Department, Ministry of Health, Malaysia \\ ${ }^{6}$ International Medical University, Bukit Jalil, Malaysia \\ ${ }^{7}$ Klinik Sri Pulai, Seremban, Malaysia
}

\begin{abstract}
Objective: The objective of this study was to examine the relationship of the users perception of Peduli sihat Scheme of the Selangor.

Methods: A validated questionnaire was utilized for this study whereby three variables of the study (patient perception, Peduli sihat scheme, Selangor, private clinics, B40) were measured using a 5-point Likert scale. 210 questionnaires were distributed to target respondents of registered clinics in Malaysia. The data were analyzed utilizing SPSS software version 21.0.

Key findings: There were 208 completed and usable responses received, which represented a $69.3 \%$ response rate. This study explored users perception of the scheme as well as users intent to support the service. This study investigates the response post implementation of Peduli sihat Scheme among the B40 group in the state of Selangor in which the outcome was satisfactory. Majority of the users support and claim that the scheme has beneficiated them.

Conclusion: Peduli sihat scheme is beneficial to the underprivileged groups in Selangor that in turn helps to reduce burden of life and improve quality of health of patients. Implementing this scheme nationwide would be a remunerative move to help strive for a better healthcare system for this country.
\end{abstract}

Keywords: Social; Peduli sihat scheme; Health; B40; Selangor

\section{Introduction}

Health care financing continues to stir debates around the world. Many low and middle income countries especially, keep on exploring different ways of financing their health systems. This is due to the fact that their health systems are chronically under-funded [1]. User fees were initially introduced at the point of service delivery in some of these countries in order to generate revenue for the running of their health systems. In some contexts, the introduction of user fees led to improvement in the quality of health care services [2]. However, the overwhelming evidence suggests that user fees constitute a strong barrier to the utilization of health care services, as well as preventing adherence to long term treatment among poor and vulnerable groups $[1,3]$. These problems led to yet another debate to look for other alternatives of health care financing.

The World Health Organization (WHO) proposes government spending on health services is 5 percent of Gross Domestic Product (GDP) [4]. The WHO 2014 report shows Malaysia's health spending rate is at 4.2 percent of GDP compared to other countries such as Cuba 11.1 percent, Brazil 8.3 percent, Vietnam 7.1 percent and Thailand 6.5 percent, which is relatively lower compared to other developing nations [5]. This fact shows that Malaysia's movement towards reaching developed nation by 2020 is still far from reaching the percentage recommended by WHO. On par with the third objective of the Global Action Plan for the Prevention and Control of NCDs 2013-2020, which is to strengthen and orient health systems to address the prevention and control of NCDs and the underlying social determinants through people-centered primary health care and universal health coverage, the government of Selangor has come up with a scheme aiming to help reduce the burden of living costs of those from the lower income group by providing accessible healthcare for free as well as to reduce the dependency of the citizens of Selangor on the federal government on primary health care. This scheme aims to decrease the cost burden of the federal government, improve the population health and to ensure that the citizens achieve better health outcome as a whole which in turn reduces morbidity and mortality rates hence rocketing productivity.

Recognizing the facts mentioned above, in the presentation of the Budget 2017 at the Selangor State Assembly, the Selangor minister announced a special health scheme to be implemented. The scheme is known as the "Peduli sihat" scheme where an initial allocation of RM125 million will be channeled to approximately 250,000 families or 1 million people of the Selangor state [6]. The target is the B40 group, the bottom group in the economic hierarchy or the household income below RM 3,000 per month. In the situation whereby there is an emergency, or when family members get sick at midnight when government clinics such as the 1Malaysia Clinic do not operate 24 hours, this scheme would come in handy. This scheme could also reduce the workload of doctors, medical assistants and nurses at the hospital emergency unit, thereby increasing the efficacy of treatment

${ }^{*}$ Corresponding author: Ahmed J, School of Post-Graduate Studies, Perdana University, Malaysia, Tel: +60389418646; E-mail: jinatahmedrizu@gmail.com

Received November 17, 2018; Accepted November 20, 2018; Published November 27, 2018

Citation: Ahmed J, Selvaganapathi G, Dinesh M, Azra N, Harikrishnan T, et al. (2018) Perception of Peduli Sihat Scheme among Peduli Sihat Users. Arts Social Sci J 9: 421. doi: 10.4172/2151-6200.1000421

Copyright: ( 2018 Ahmed J, et al. This is an open-access article distributed under the terms of the Creative Commons Attribution License, which permits unrestricted use, distribution, and reproduction in any medium, provided the original author and source are credited. 
in government hospitals. With a Healthy Peduli card introduced by the Selangor government, the card holders can simply go to any registered clinic near their house.

The Peduli sihat scheme managed by Selgate Corporation as Third-Party Healthcare Administrator will fund primary care for every eligible family of up to RM 500 a year. The recipients of this scheme can get treatment at 1,000 registered clinics in Selangor and Klang Valley. Those who are born or have been living for more than 10 years in Selangor are eligible to participate in the scheme. Registration can be made at the Office of the State Assemblyman, Local Authority and District and Land Offices, registered clinics including online registration with proof of income or confirmation. Each participant will receive a Health Care Card health card. Holder of the Peduli sihat main account and its dependents - wives and children under the age of 21 may receive a general practitioner's treatment at registered clinics according to the applied proficiency and qualification. Clinics registered with Peduli sihat will charge doctors' consultation fees which will not burden the people in line with the fees set by the Malaysian Medical Association (MMA) [7].

Non communicable diseases have been an alarming and rising global public health problem affecting all countries regardless of income [8]. Data and statistics on the National Health and Morbidity Survey (NHMS) in 2015 have shown that the extensiveness of noncommunicable diseases are persistently ascending. The prevailing estimation of adult living with diabetes are 3.5 million, 6.1 million with hypertension, 6.1 million with hypertension, 9.6 million with hypercholesterolemia and 3.3 million with obesity [9]. The extensively increasing number of non-communicable diseases has been one of the biggest challenges to the present day health system in Malaysia. In spite of the multi coordinated effort done by the government, public and private sector to combat the rise of non-communicable diseases, the numbers have yet to show a decrease in prevalence.

Primary health care, as elucidated by the Alma Ata Declaration is, an essential health care based on practical, scientifically sound and socially acceptable methods and technology made universally accessible to individuals and families in the community through their full participation and at a cost that the community and country can afford. It is the first level of contact of individuals, the family and the community with the national health system, bringing health care as close as possible to where people live and work [10]. The primary health care system in Malaysia is a two-tier system comprising health clinics with a comprehensive range of primary medical care services (klinik kesihatan), and community clinics (klinik desa) with services largely limited to maternal and child health. A variation on the Klinik Desa is the 1Malaysia clinic, situated in high density, low income urban and semi-urban areas. Each Klinik Kesihatan serves a population of approximately 15,000 to 20,000 persons, while each Klinik Desa provides services for approximately 2,000 to 4,000 mothers and children [11]. There are 985 health clinics, 1,864 community clinics, and 1091Malaysia clinics [12].

Today in healthcare facilities, we have many systems and the numbers continue to grow due to functional needs, but we continue to have a large gap on patient care systems despite its obvious benefits. Inadequate and inconsistent funding's to primary health clinics in Malaysia results in having limited resources of medications to cater individual needs. Inconvenient distance of the primary healthcare clinics is also a difficulty for those in the lower income group who usually depend on public transportation to get from one place to the other. Extended period of waiting hours were a concern to the patients due to the higher doctor to patient ratio which is currently at 1:632 [13]. The World Health Organization recommends at least 23 healthcare workers per 10,000 population, which is roughly a ratio of 1:435 [14]. The Peduli sihat scheme aims to provide accessible quality healthcare to those from the lower income group and to reduce the dependency of the Selangor citizen's towards government hospitals and clinics. This is a middle ground for the private sectors, federal government as well as the citizens. All parties were expected to be able to gain beneficiaries from this scheme implementation.

\section{Methodology}

\section{Study design and context}

This study was conducted via a cross-sectional survey design. It was carried out among the patients from private clinics in Selangor Darul Ehsan. The surveys were conducted among clinics in this region and a total of 300 questionnaires were distributed.

\section{Participant identification and recruitment}

Self-administrated questionnaire surveys were distributed to participants fulfilling inclusion criteria in Selangor. The inclusion criteria were, local citizen of Malaysia, those who gave consent to take part in the study, mentally stable, and patients whom own and have used the Peduli sihat card. Those excluded criteria were patients suffering from certain mental illnesses, did not consent to take part in the study, Non-Malaysian respondents and those whom had never owned and used the Peduli sihat card. A sample size of 208 participants was deemed adequate to obtain significant findings based on Krejzie and Morgan population table. To account for a good response rate, study population was targeted at 300 respondents.

\section{Instrumentation and data collection}

The questionnaire consisted of 24 items and was divided into 4 separate sections. The first part consisted of demographic details, whereas the second part of 11 item explored consumer satisfaction of panel services. The third section contained 5 items evaluating user satisfaction with administrator services and finally the last part contained 3 item explored users intent to support and use the service. The items in the questionnaire used a 5-point Likert scale. Content validity was assessed by a panel of general practitioners and academics in public health to select the best questions in terms of clarity, accuracy of the items used for health information features and patient attitudes. A pilot study completed by 30 respondents gave an average Cronbach alpha confirming adequate reliability. The finalized version was used for data collection in the general sample.

Out of the 300 questionnaires distributed to the patients in private panel clinics, 208 questionnaires were returned completed, yielding a response rate of $69.3 \%$.

\section{Statistical analysis}

Data analysis was done using 'Statistical Package for Social Sciences' (SPSS) Version 22.0. Descriptive and inferential analytical tests were computed using this software. Statistical significance level was taken at the $\mathrm{p}$ value $<0.05$. For bivariate analysis, the data were analyzed by using Pearson Chi-Square test for statistical difference of the categorical variables. Finally, for multivariate analysis the simple logistic regressions were used to predict the final model. 


\section{Ethical consideration}

Written consent was obtained from participants prior to participating in this study. Further approval was also obtained the relevant ethics committee.

\section{Results}

Based on the social demographic analysis in the table above, it can be concluded that there was an almost equal participation between both the genders (Table 1). Male respondents comprised of 50.5\% while female respondents were slightly lower at $49.5 \%$ bridging a gap of $1 \%$ in comparison to one another. Looking into races, the Malay ethnicity had the highest level of involvement in this survey of $52.4 \%$ followed by Indians $33.2 \%$, Chinese $13.5 \%$ and the least whom took part in this survey were other races $1 \%$. Marital status were also taken into account in this study whereby the highest prevalence of patients coming to the clinic were married at $67.3 \%$ followed by single $22.6 \%$ and finally the least numbered were divorced accounting to $10.1 \%$. Additionally, there were four age groups that took part in this survey ranging from 21 year old up till above 50 . The highest participation belonged to the 31-40 year old age group which were $37.0 \%$ followed by the youngest age group at $27.9 \%, 41-50$ at $11.1 \%$ and the least belongs to above 50 at $2.9 \%$. Finally, education level were also valued in this survey. Based on the analyzed data, it can be presumed that the majority of patients that visits clinics has at least completed secondary school education and more (Table 2).

Based on the consumer's satisfaction analysis, it can be seen that the average cost per visit ranges highly between RM 25-75. RM 2550 shows the highest frequency of $45.7 \%$ followed by RM $50-75$ at $40.9 \%$. Below RM 25 and above RM 75 are the least costs for per visit at $5.8 \%$ and $7.7 \%$. Looking into the need to expend money at the panels, surprisingly a very high amount of users claim the need to spend additional cost despite of using the scheme. $87.5 \%$ of users are willing to change to a healthier lifestyle where else $12.5 \%$ states otherwise. Looking at the reference of the core administration body to oversee the scheme or an individual agency under $\mathrm{MOH}$, more than half of the

\begin{tabular}{|l|c|c|}
\hline Categories & Frequency & Percentage (\%) \\
\hline Gender & 105 & 50.5 \\
\hline Male & 103 & 49.5 \\
\hline Female & 109 & 52.4 \\
\hline Ethnicity & 28 & 13.5 \\
\hline Malays & 69 & 33.2 \\
\hline Chinese & 2 & 1.0 \\
\hline Indians & \multicolumn{2}{|l|}{} \\
\hline Others & 47 & 22.6 \\
\hline Marital Status & 140 & 67.3 \\
\hline Single & 21 & 10.1 \\
\hline Married & \multicolumn{2}{|l|}{} \\
\hline Divorced & 58 & 27.9 \\
\hline Age & 77 & 37.0 \\
\hline $21-30$ & 44 & 11.1 \\
\hline $31-40$ & 6 & 2.9 \\
\hline $41-50$ & 113 & 5.8 \\
\hline Above 50 & 68 & 7.2 \\
\hline Education Level & 15 & 54.3 \\
\hline Without formal education & 113 & 32.7 \\
\hline Primary schooling & & \\
\hline Secondary Schooling & & \\
\hline University/College & & \\
\hline
\end{tabular}

Table 1: Equal participation between both the genders.

\begin{tabular}{|c|c|c|}
\hline Categories & Frequency & Percentage (\%) \\
\hline \multicolumn{3}{|c|}{ Average costs per visit } \\
\hline Below 25 & 12 & 5.8 \\
\hline RM 25-50 & 95 & 45.7 \\
\hline RM 50-75 & 85 & 40.9 \\
\hline Above RM 75 & 16 & 7.7 \\
\hline \multicolumn{3}{|c|}{ How often you need to raise money } \\
\hline Rarely & 97 & 46.6 \\
\hline Seldom & 92 & 44.2 \\
\hline Often & 15 & 7.2 \\
\hline Always & 4 & 1.9 \\
\hline \multicolumn{3}{|c|}{ Willingness to change to a healthier lifestyle } \\
\hline Yes & 182 & 87.5 \\
\hline No & 26 & 12.5 \\
\hline \multicolumn{3}{|c|}{$\begin{array}{l}\text { Concurrence nationalization of the scheme by the government and the ministry o } \\
\text { health as the implementing agency }\end{array}$} \\
\hline Yes & 180 & 86.5 \\
\hline No & 28 & 13.5 \\
\hline \multicolumn{3}{|c|}{$\begin{array}{l}\text { Preference of the core administration body to oversee the scheme or an individua } \\
\text { agency under } \mathrm{MOH}\end{array}$} \\
\hline Under $\mathrm{MOH}$ & 141 & 67.8 \\
\hline Individual agency & 67 & 32.2 \\
\hline
\end{tabular}

Table 2: Consumer satisfaction of panel services.

consumers, $67.8 \%$ prefer to have it under Ministry of Health in contrast with $32.2 \%$ favors to run the scheme under an individual agency (Table 3).

Based on the secondary portion of the consumer's satisfaction of panel services, it can be concluded that the vast majority agree that this scheme has helped improve life and is beneficiary to the people of Selangor. $87.1 \%$ of the scheme users agree that the panel clinics are easily accessible. A total of $89.4 \%$ accord that the scheme has a user friendly service process. In terms of the application and verification process, $87 \%$ agrees that the process runs seamlessly without going through much hardship and complicated process and procedures. Looking into the efficacy of the scheme in providing immediate treatment for emergency situations, generally $82.2 \%$ has found the scheme beneficial in addressing this issue. More than half users, $78.9 \%$ acknowledge that this service has helped them to receive immediate treatment for emergency situations. To culminate the response from the users, it can be concluded that this scheme has helped and beneficiated the users as $\sim 80 \%$ of the respondents have responded in such manner (Table 4 ).

The third part of the survey assesses users intent to support and use the service. Overall this section has a slightly lower satisfaction rate as compared to the previous one. In this category, the highest satisfaction rate is at $82.2 \%$ whereby of the users agree that Peduli sihat scheme registration process is easy followed by the rest which declines steadily up till the very last questionnaire. Looking at the least satisfied context, only $65.9 \%$ of users agree that complains are responded in a transparent and effective manner. $14.4 \%$ disagree that the scheme response to complaints in a transparent and effective manner while $19.7 \%$ are neutral about the issue.

\section{Discussion}

\section{Consumer satisfaction of panel services}

The current study conducted provides an understanding of the perception regarding the Peduli sihat scheme among the Peduli sihat users. The results of this study show that the end users of this scheme coherently agree that this scheme is generally beneficial to the patients 


\begin{tabular}{|c|c|c|}
\hline Categories & Frequency & Percentage (\%) \\
\hline \multicolumn{3}{|c|}{ Easy access to panel clinics } \\
\hline Strongly disagree & 6 & 2.9 \\
\hline Disagree & 8 & 3.8 \\
\hline Neutral & 13 & 6.3 \\
\hline Agree & 111 & 53.4 \\
\hline Strongly agree & 70 & 33.7 \\
\hline \multicolumn{3}{|c|}{ User friendly service process } \\
\hline Strongly disagree & 3 & 1.4 \\
\hline Disagree & 5 & 2.4 \\
\hline Neutral & 14 & 6.7 \\
\hline Agree & 112 & 53.8 \\
\hline Strongly agree & 74 & 35.6 \\
\hline \multicolumn{3}{|c|}{ Reduced load towards user } \\
\hline Strongly disagree & 3 & 1.4 \\
\hline Disagree & 4 & 1.9 \\
\hline Neutral & 20 & 9.6 \\
\hline Agree & 110 & 52.9 \\
\hline Strongly agree & 71 & 34.1 \\
\hline \multicolumn{3}{|c|}{ Easy application and verification process } \\
\hline Strongly disagree & 1 & 0.5 \\
\hline Disagree & 3 & 1.4 \\
\hline Neutral & 27 & 13.0 \\
\hline Agree & 107 & 51.4 \\
\hline Strongly agree & 70 & 33.7 \\
\hline \multicolumn{3}{|c|}{ This service has educated me in the practice of disease prevention } \\
\hline Strongly disagree & 1 & 0.5 \\
\hline Disagree & 7 & 3.4 \\
\hline Neutral & 29 & 13.9 \\
\hline Agree & 105 & 50.5 \\
\hline Strongly agree & 66 & 31.7 \\
\hline \multicolumn{3}{|c|}{ This service has given me immediate treatment for emergency situations } \\
\hline Strongly disagree & 1 & 0.5 \\
\hline Disagree & 5 & 2.4 \\
\hline Neutral & 38 & 18.3 \\
\hline Agree & 90 & 43.3 \\
\hline Strongly agree & 74 & 35.6 \\
\hline
\end{tabular}

Table 3: Consumer satisfaction of panel clinics.

and a vast majority agree that they are satisfied with the outcome of this venture.

Scrutiny in consumer appeasement with health care scheme is based mainly on the premise that it is meaningfully related to health behavior and other health attributes [15-18]. This study addresses the issue by focusing on one dimension of consumer satisfaction, satisfaction with physician provided services, as criterion variable and postulating it as a function of prior satisfaction on the same dimension, concurrent assessment of the availability of services, use of health services and characteristics of the consumer and health delivery system. The relevancy of this finding is enhanced by the fact that all of the data reveals that patients from all age groups are very satisfied with the services over the span period of two years. About $87.1 \%$ of the were satisfied with the service of the health panel. The same pattern had been observed in all the other criteria's in the consumers satisfaction section. Equally, the questionnaire saw no difference in the response for the education for the consumers in terms of disease prevention. However, the quantitative study revealed that the almost half of consumers were required to add on money with regards to the service provision. This is rather inconvenient for most of the B40 end users and it doesn't meet the mission of the development of this scheme. Perhaps more research needs to be done to make some improvement in this area. Most clients

\begin{tabular}{|c|c|c|}
\hline Categories & Frequency & Percentage (\%) \\
\hline \multicolumn{3}{|c|}{ The registration of the scheme in system is easy } \\
\hline Strongly disagree & 9 & 4.3 \\
\hline Disagree & 6 & 2.9 \\
\hline Neutral & 22 & 10.6 \\
\hline Agree & 107 & 51.4 \\
\hline Strongly agree & 64 & 30.8 \\
\hline \multicolumn{3}{|c|}{ The administrator of the scheme is always polite } \\
\hline Strongly disagree & 4 & 1.9 \\
\hline Disagree & 15 & 7.2 \\
\hline Neutral & 24 & 11.5 \\
\hline Agree & 99 & 47.6 \\
\hline Strongly agree & 66 & 31.7 \\
\hline \multicolumn{3}{|c|}{ Adequate campaigns are made in making customers aware of the service } \\
\hline Strongly disagree & 14 & 6.7 \\
\hline Disagree & 20 & 9.6 \\
\hline Neutral & 27 & 13.0 \\
\hline Agree & 86 & 41.3 \\
\hline Strongly agree & 61 & 29.3 \\
\hline \multicolumn{3}{|c|}{ Adequately respond to customer suggestions } \\
\hline Strongly disagree & 8 & 3.8 \\
\hline Disagree & 24 & 11.5 \\
\hline Neutral & 38 & 18.3 \\
\hline Agree & 85 & 40.9 \\
\hline Strongly agree & 53 & 25.5 \\
\hline \multicolumn{3}{|c|}{ Respond to complaints in a transparent and effective manner } \\
\hline Strongly disagree & 11 & 5.3 \\
\hline Disagree & 19 & 9.1 \\
\hline Neutral & 41 & 19.7 \\
\hline Agree & 80 & 38.5 \\
\hline Strongly agree & 57 & 27.4 \\
\hline
\end{tabular}

Table 4: Users intent to support and use the service.

in the state of Selangor perceive that nationalization of the scheme by the government and the ministry of health as the implementing agency would be a good movement. Patrons also prescribe that they would opt for the scheme to be managed under the Ministry of Health instead of an individual agency under $\mathrm{MOH}$.

\section{Users intent to support and use the service}

Patient-centered care is comprehensively regarded as one pillar of a high performing, high-quality health care system [19]. In the health care literature the terms communication and interaction are used interchangeably [20]. Communication failures between clinicians are the most common primary cause of dissatisfaction in health care [21]. Within healthcare, quality care has been defined by the Institute of Medicine as care that is safe, effective, timely, efficient, equitable and patient-centered [22]. Patient-centered care is defined as care that is respectful of and responsive to individual patient preferences, needs and values, and ensuring that patient's values guide all clinical decisions. Patient centered-care encompasses the individual experiences of a patient, the clinical service, the organizational and the regulatory levels of health care [23]. Healthcare organizations that are patient-centered engage patients as partners and hold human interactions as a pillar of their service [23]. As healthcare focuses on providing services that are patient-centered and methods to ensure this occurs, patients voice and experience of health care provision is increasingly being sought from an organizational quality improvement perspective. Patients are being surveyed on their healthcare experience across interpersonal areas such as being provided the opportunity by their health professional to ask questions, the level of involvement in their own care and whether they 
Citation: Ahmed J, Selvaganapathi G, Dinesh M, Azra N, Harikrishnan T, et al. (2018) Perception of Peduli Sihat Scheme among Peduli Sihat Users. Arts Social Sci J 9: 421. doi: 10.4172/2151-6200.1000421

Page 5 of 5

were shown courtesy, treated with respect and listened to carefully by their health professional $[23,24]$.

\section{Conclusion}

The study set out to examine the users perception of Peduli sihat scheme. This was achieved by assessing the views of users from various clinics across the state of Selangor. The Peduli sihat scheme was seen by all participants of the study to be beneficial. The B40 group were satisfied with the care given them, according to the survey. However, some of the clients have reported in poor customer service such as inadequate respond to consumers suggestions and lack of response to clients in transparent manner. Although there are room for improvement in the future, this scheme sounds very promising and holds a greats benefit as primary care if implemented nationwide that could help reduce health disparities within the B40 group. With that being said, there is the need for further research to cover a lot more of the users in more districts and in more and private facilities to help determine the influence and beneficence of the Peduli sihat scheme on the providers.

\section{References}

1. James CD, Hanson K, McPake B, Balabanova D, Gwatkin D, et al. (2006) To retain or remove user fees? Reflections on the current debate in low-and middle-income countries. Appl Health Econ Health Policy 5: 137-153.

2. Lagarde M, Palmer N (2006) Evidence From Systematic Reviews to Inform Decision Making Regarding Financing Mechanisms that Improve Access to Health Services for Poor People: A Policy Brief Prepared for the International Dialogue on Evidence-Informed Action to Achieve Health Goals in Developing Countries (IDEA Health). World Health Organization: Geneva.

3. Palmer N, Mueller DH, Gilson L, Mills A, Haines A (2004) Health financing to promote access in low income settings-how much do we know? Lancet 364 : $1365-1370$.

4. Xu K, Priyanka S, Alberto H (2011) The Determinants of Health Expenditure

5. Richard R (2018) Malaysia Economic Monitor.

6. Kad Peduli Sihat Selangor (2016) Sinar.

7. Skim Peduli Sihat (2017) Peduli Sihat.

8. Swinburn B, Sacks G, Hall K, McPherson K, Finegood DT, et al. (2011) The global obesity pandemic: shaped by global drivers and local environments. Lancet 378: 804-814

9. Min CC (2016) National Strategic Plan for Non-Communicable Diseases (NSPNCD) 2016-2025.

10. WHO (2013) Declaration of Alma-Ata. Alma-Ata USSR; 1978.

11. Safurah J, Kamaliah MN, Fauziah ZE, Lee FS (2013) Primary Health Care Key to Intersectoral Action for Health and Equity.

12. MOH Malaysia (2012) Health Facts

13. Department of Statistics Malaysia 2017

14. World Health Organization (2018) Health workforce Millennium Development Goals.

15. Aday LA, Eiehhorn R (1972) The Utilization of Health Services. Indices and Correlates: A Research Bibliography. National Center for Health Services Research and Development. U,S, Department of Health, Educa tion and Welfare, DHEW Publication No. (HSM) 73-3003.

16. Lebow JL (1974) Consumer assessment of the quality of medical care. Med Care 12: 328-337.

17. Mechanic D (1968) Medical Sociology. Macmdlan, New York

18. Ware JE, Snyder MK, Wright WR (1976) Development and Validation of Scales to Measure Patient Satisfaction with Health Care Services, Vol. 1 of a Final Report/part A. School of Medicine, Southern Illinois University.

19. Institute of Medicine (2001) Crossing the quality chasm: a new health system for the 21st century. Washington (DC): National Academies Press.

20. Fleisher S, Berg A, Zimmerman M, Wuste K, Behrens J (2009) Nurse-patient interaction and communication: A systematic literature review. J Public Health 17: $339-353$

21. Frampton SB, Charmel PA (2009) Putting patients first: best practices in patient-centered care.

22. Australian Commission on Safety and Quality in Health care (2011) patientcentered care: improving quality and safety through partnership with patients and consumers.

23. The Commonwealth Fund (2011) The Commonwealth International Health Policy Survey.

24. Department of Health Victoria (2011) Victorian Satisfaction Monitor Year 10 Annual Report July 2010 to June 2011. 